\title{
Modern Means and Technologies for Estimation of Results of Training
}

\author{
Zhanna V. Smirnova, Olga 1. Vaganova, Nina V. Frolova, Marina V. Ogorodova, and Vasiliy V. Rozarenov \\ Minin Nizhny Novgorod State Pedagogical University (Mininsky University), Nizhny Novgorod, Russian Federation
}

\begin{abstract}
The article discusses the use of modern tools and technologies for assessing learning outcomes. Evaluation of learning outcomes is inextricably linked with the quality of education provided by an educational institution. It is noted that today there is no single interpretation of the concept of "quality of education". Because of the introduction of the competence approach, graduates now form not just a certain amount of knowledge and skills, but the ability to use it, apply the experience gained in practice, so modern assessment should be fundamentally new and different from traditional methods. The features of the competency assessment system are determined. The basic provisions of the assessment methodology are established and on their basis; we have identified the components of the model of the system of automated assessment of professional competencies. The principles of constructing the competency assessment model were singled out. The analysis of existing modern means of estimation is carried out. Among them, the methods specific to the authentic approach were highlighted, as well as the advantages of using the electronic platform Moodle for conducting the evaluation procedure.
\end{abstract}

\section{Introduction}

In the modern world, demands are growing both for the content of education, the forms of its implementation, pedagogical technologies and methods of instruction, and for modern means of evaluating educational results. All classifications of training methods involve checking the knowledge of students, evaluating their activities and correcting them when necessary. The subject we are considering is undoubtedly relevant, since the formation of an independent person and a highly qualified specialist that can be easily oriented in life and professional activity is impossible without the use of modern tools and technologies to identify the effectiveness of student learning. The quality of education as a whole also depends on this. The purpose of this study is to generalize and supplement information on modern tools, technologies and methods for assessing the knowledge of students at the current stage of training.

\section{Evaluation of learning outcomes and quality of education within the competence approach}

Evaluation of learning outcomes and quality of education are inextricably linked. The problem of quality assessment is ubiquitous in Russia, and the concept of "quality of education" is multidimensional and subjective [1]. At the moment there is no single recognized interpretation of this concept. We will adhere to the following definition. The quality of education is an integral characteristic of the education system, reflecting the degree to which educational outcomes correspond to regulatory requirements, social and personal expectations [2].

The framework of the competence approach makes it necessary to modify the assessment of the quality of the graduates' preparation; therefore, fundamentally new technologies for assessing the characteristics acquired by trainees are required [3]. In the new educational paradigm, students do not simply form a certain amount of knowledge and skills, but the ability to use it in practice, that is, a set of competences is formed, and therefore the evaluation must take place in a different way than traditional.

It should also be noted that, to date, the problem also lies in the lack of a methodological and scientific and methodological basis for assessing competences [4].

In modern Russia, almost every educational institution faces the problem of assessing professional competencies, which often affects the quality of the students' education. Formation and development of competencies is due to the content of training, the educational environment of the institution and the educational technologies that the educational institution uses.

Traditional valuation means should be replaced with new ones that meet the quality requirements of specialists [5].

\section{Analysis of modern assessment tools}

* Corresponding author: z.v.smirnova@mininuniver.ru 
The world educational community has long been discussing and testing various types of assessment, forms and technologies for monitoring the results of the educational process. To date, there is a so-called authentic, that is, genuine, real assessment or assessment of the real achievements of students. Thanks to the authentic methods of evaluation, it becomes possible to reflect easily the absolute and relative indicators of personal achievement in the educational process [6].

Different models of authentic assessment are aimed at identifying the objectively existing level of the formation of professional competencies, difficulties in mastering the educational material, the success of development of thinking activity, and critical attitude to learning activity. Authentic assessment helps to form a culture of critical thinking, logic, ability to analyze, generalize, systematize, classify the necessary information [7].

One of the authentic methods of evaluation is the rating system of evaluation, where the main principles are the completeness of the provision of educational material, which is determined by the introduction of mandatory and additional points for determining the student's rating.

The ratings of the rating are as follows:

- relativity, which consists in the fact that the total number of points on a topic is determined depending on the hours allocated for studying it and the significance of a particular topic in comparison with others;

- openness. This principle allows the student to become more open and involved in the learning process. Here the subjectivity of the teacher decreases in evaluation, stimulation of the competitive moment takes place, which reflects objectively existing competition, for example, in the labor market;

- transparency. The rating makes it possible to single out the status of an individual student against the background of the entire training group and to determine the extent to which the particular student has approached the final assessment on which he counts;

- simplicity and accessibility. The rating system of assessment allows you to consider your labor results as a way to show yourself, to become attractive in the labor market [8].

This system allows you to demonstrate the range of knowledge and skills, the formation of the competences of the student. It is impossible not to single out in this case the principle of voluntariness, because it is thanks to him that the control of results becomes a way of rationally determining personal ratings [9].

The study of the foreign experience of using the rating system shows positive aspects. This organization of training gives students freedom of choice. They can themselves determine the sequence in which they will study the various curricular disciplines from the basic educational program in a particular area of training or specialty.

Successful students, thus, can master the educational program for a shorter period.

It should be noted that under the influence of technology, when evaluating educational results, modern computer technologies are also used. Speaking about this, we can not fail to mention electronic platforms, through which an intermediate check of knowledge can be carried out, and important competencies can also be formed.

The most common electronic platform and the most commonly used is Moodle, because it is easy to use and does not require any additional costs.

In addition, it fits into the competence paradigm.

Competent-oriented assessment tools are subject to certain requirements. The main include:

- objectivity;

- reliability;

-justice;

- validity;

- timeliness;

- effectiveness [10].

One of the main means of control in recent years is testing.

It is customary to refer to a pedagogical test system as a system of test tasks of a specific form that has a certain content with different levels of difficulty and a methodology for carrying out the testing procedure and processing its results in order to identify an objective evaluation of students' learning achievements [11].

The test task always contains a problem that the student must be allowed to solve.

The main difference between test tasks and ordinary tasks is their manufacturability. That is, the task has a clear answer and is evaluated as standard. The answer to the pedagogical test is a brief judgment on the content of the question.

Thus, test tasks are the elements of which the test is composed as a system. There are a number of features that differentiate tasks in the test form from the others:

- target;

- brevity of the task;

- manufacturability;

- logical construction of the statement;

- the certainty of the place for answers;

- the same rules for assessing responses;

- the correct location of the elements of the job;

- the same instruction for each subject;

- adequacy of the instruction to the form and content of the task [12].

The certainty of the content means that the test uses only the control material that corresponds to the contents of the academic discipline.

However, the effectiveness of this practice is in doubt, since it does not allow one to analyze fully the level of preparedness of students. While the teacher still receives the necessary data, it is quite difficult to identify gaps in knowledge in certain areas. Therefore, in the Moodle system, it is possible to create several types of test questions. For example, such as:

- Multiple choice procedure;

- establishing compliance;

- true False;

- the possibility of a short answer;

- the possibility of a numerical response;

- an essay [13].

Using such tool as an essay allows you to reflect the subjective impression and thoughts of the author on a 
specific topic and does not require an exhaustive or defining interpretation of the topic. The essay, unlike other types of assignments, does not have a specific standard that students could take as a model. Thus they show the maximum degree of creativity. Characteristics of the essay is based on imagery, mobility of associations, laconism. The advantage of this kind of independent work of students is that it gives students the opportunity to express freely their views about pedagogical events, facts, phenomena or problems, to operate with arguments in order to defend their position, their opinion [14].

With the help of the "essay" tool in remote technologies, productive levels of knowledge are controlled, which means creativity, probabilistic, abstract and methodological knowledge. Thus, students move to such a significant stage of cognitive activity as research, which takes a considerable place throughout the entire training. The use of such component excludes an element of randomness. Intuition loses its significance when writing an essay [15]. It is also an opportunity for the student to consider more deeply the topic under study, to delve into the question and reflect on it.

The objective criteria for evaluating the essay include:

- the ability to fully reveal the topic and problems;

- compliance with the work structure;

- knowledge and understanding of theoretical material;

- the ability to analyze and evaluate information;

- it is logical and connected to build proposals, correctly express their position;

- the ability to justify the conclusions [16].

All the variety of tools provided by Moodle to assess the activities of students allows you to implement various ideas in the organization of the learning process.

4 Proposals for the development of an evaluation of the results of education

Features of the competence assessment system:

- systematic approach to the evaluation of educational outcomes (that is, determining the level of the formation of general and professional competencies should be comprehensive);

- the planned results (competencies) for the mastering of the basic educational programs should be used as a substantive and criterial basis for evaluation;

- evaluation of achievements is characterized by the ability to perform professional tasks;

- monitoring of the level of mastering of professional competencies must be constantly monitored [17];

- using a tiered approach to the development of planned results and tools, as well as their provision;

- the dynamics of mastering competencies should be characterized by a special cumulative rating system (portfolio). So it's easiest to track positive or negative dynamics;

- active and interactive forms of learning should be used in the learning process;

- project technologies should be actively used [18].

As modern education develops under the influence of informatization and technological development of society, the evaluation system must also be automated [19].

The basic provisions of the assessment methodology include:

- in order to determine the level of proficiency, it is necessary to assess the key features of the cognitive and functional components of competence;

- for processing input data, generating summary analysis and monitoring sheets, software is used whose mathematical apparatus is built using mathematical and statistical methods [20];

- the level of vocational training of students must comply with the GEF [21].

Based on these provisions, it is possible to distinguish the components of the model of the system of automated assessment of professional competencies:

- a target component that contains the purpose and requirements (Federal State Educational Standard, consumers of educational services) [22];

- the resource component ensures the uninterrupted operation of the model of automated estimation of professional components [23]. Contains:

1. regulatory and legal support;

2. methodological support;

3. information support;

4. staffing;

5. organizational support [24].

- a diagnostic component that includes methods, tools, methods, evaluation criteria and a set of evaluation tools;

- the software component is a description of the technology of automated assessment, which includes three phases:

1. preparation;

2. treatment;

3. analysis and diagnosis.

- in the control-reflective component, a monitoring function is established, the role of which is to verify the reliability of the evaluation results [25].

We will refer to the principles of model building the following:

- the integrity of the system should be ensured (the essence should be to assess the level of mastering the academic disciplines and assess the level of mastering competencies);

- supporting the development of the education system (activities should focus not on checking and monitoring the state of the system, but on assessing the dynamics of its development and managing the quality of education);

- competency assessment should be based on a systematic approach;

- some possible distortions must be taken into account (obtaining incorrect evaluation results due to the lack of objective criteria and evaluation procedures) [26].

The purpose of the assessment is to determine the level of mastering the professional competence for compliance with this level with the required standards. The target component of the assessment system is the set of requirements that are presented to graduates from the state, society, potential employers, while keeping in mind the specificity of the regional economy. 
Most often, the main components in assessing professional competencies are: requirements for the graduate; a competence model of the graduate; funds of valuation means; levels of competence formation.

\section{Conclusions}

Existing tools and technologies for evaluating learning outcomes have many advantages and their joint use makes it possible to simplify the assessment process as much as possible, making it more convenient and intensive.

The proposed recommendations for the evaluation of educational outcomes are favorable not only for a correct assessment of the results of the education process, but also for the continuous monitoring of the development of professional competencies. And this contributes to the rapid adjustment and individualization of the learning process.

\section{References}

1. M. N. Gladkova, O. I. Vaganova, Problems of Modern Pedagogical Education 57(1), 3-9 (2017)

2. E. A. Aleshugina, Bulletin of Kostroma State University. O.N. Nekrasov 4(14), 11-14 (2007)

3. I. B. Bicheva, O. M. Filatova, Bulletin of the University of Minin 3(20) 5 (2017)

4. O. I. Vaganova, O. E. Ermakova, Bulletin of the University of Minin 4(6) (2014)

5. O. I, Vaganova, M. I. Koldina, A. V. Trutanova The Baltic Humanities Journal 2(19), 97-99 (2017)

6. A. V. Gushchin, Bulletin of the University of Minin 3 (11) (2015)

7. A. Zulkharnaeva, N. Vinokurova, I Krivdina, N. Martilova, M. Badin, Man in India 97(15), 559-571, (2017)

8. E. Yu. Iltaldinova, I. F. Filchenkova, S. V. Frolova, Bulletin of the University of Minin 3(20), 2, (2017)

9. D. S. Kostylev, E. Y. Saliaeva, O. I. Vaganova, L. I. Kutepova, Azimuth of scientific research: pedagogy and psychology 5(15), 80-82, (2015)

10. M.P. Konovalova, Saratov region - 80 years: history, experience of development, growth prospects Collection of proceedings on the results of the International Scientific and Practical Conference: in 3 parts, 54-55, (2016)

11. S. N. Kaznacheeva, E. A, Chelnokova, I. B. Bicheva, Z. V. Smirnova, A. L. Lazutina, Man in India 97(15), 191-199, (2017)

12. L.I. Kutepova, Didactic conditions for the formation of professional competences. Modern trends in the development of technological and economic education (N. Novgorod, 2014)

13. Z. V. Smirnova, O. I., Vaganova, A. V. Trutanova, Karelian scientific journal 3(20), 74-77, (2017)
14. Z. V. Smirnova., M. L. Gruzdeva, O. G. Krasikova, Bulletin of the University of Minin 4(21), 3, (2017)

15. E. I. Yakovleva, N. A. Shobonov, Modern problems of science and education $\mathbf{6 ,},(2016)$

16. S. N. Yashin, N. I. Yashina, M. V. Ogorodova, Z. V. Smirnova, S. N. Kuznetsova, I. N. Kuznetsova, Man in India 97(9), 37-42 (2017)

17. E. V. Yashkova, N. L. Sineva, A. A Shkunova., N. V. Bystrova, Z. V. Smirnova, T. V. Kolosova, International Journal of Environmental and Science Education 11(1), 4650-4659, (2016)

18. Z. V Smirnova, O. Vaganova, S. Shevchenko, A. Khizhnaya, M. Ogorodova, M. Gladkova, IEJMEMathematics Education 11(10), 3469-3475, (2016)

19. V. M. Sokolov, N. F. Ugodchikova, E. A. Aleshugina, D. A. Loshkareva, Competent-oriented improvement of the additional language educational program in a technical university (Monograph. Nizhny Novgorod, 2013)

20. A. A. Fedorov, G. A. Paputkova, E.Y. Ilaltdinova, I.F. Filchenkova, M.Y. Solovev Man in India 97(11), 101-114 (2017) 